DOI: https://doi.org/10.24867/05FA10Aleksandrov

\title{
PEJZAŽNO-ARHITEKTONSKO UREĐENJE KOMPLEKSA HOTELA „TAMIŠ““ U PANČEVU
}

\section{LANDSCAPE- ARCHITECTURAL ARRANGEMENT OF THE HOTEL COMPLEX "TAMIŠ" IN PANČEVO}

\section{Anđela Aleksandrov, Fakultet tehničkih nauka, Novi Sad}

\begin{abstract}
Oblast - ARHITEKTURA
Kratak sadržaj - Jedan od najvećih značaja vegetacije u urbanoj sredini jeste taj što poboljšava stvorene, a $i$ prirodne uslove. Stvaranje vrtova na horizontalnim $i$ vertikalnim površinama objekata, bilo da su oni postojeći ili novoplanirani, u poslednje vreme vrlo je važno za podržavanje održivosti. Strategije koje se baziraju na principima održivog razvoja doprinose zaštiti klime $i$ uštedi energije $i$ obezbeđuju bolji kvalitet života za stanovnike. $U$ radu su pored osvrta na istorijski kontekst krovnih $i$ vertikalnih vrtova, prikazane njihove klasifikacije i najbitnije karakteristike $i$ funkcije. Istražena je $i$ analizirana primena ove vrste ozelenjavanja na hotelima u urbanim područjima, i njihov doprinos poboljšanju kvaliteta uslova života u toj sredini. Sanacijom postojećih objekata, $u$ mesto izgradnjom novih, odnosno implementacijom pejzažnih struktura kroz arhitektonska rešenja sprečava se, pored ostalog, i uništavanje zelenih struktura koje su od izuzetnog značaja za očuvanje biodiverziteta i kvalitetne životne sredine.
\end{abstract}

Ključne reči: održivost, krovni vrt, vertikalni vrt, pejzažna arhitektura

Abstract - One of the greatest importance of vegetation is that it improves climatic conditions in the urban environment. The creation of gardens on the horizontal and vertical surfaces of buildings, whether they are existing or newly-planned, has recently been very important for supporting sustainability. Strategies based on the principles of sustainable development contribute to the protection of climate protection and efficient energy use, thus providing a better quality of life for residents. In addition to reviewing the historical context of the roof and vertical gardens, the paper presents their classifications and the most important characteristics and functions. The application of this type of greenhouse enrichment to hotels in urban areas and their contribution to improving the quality of living conditions have also been investigated and analyzed. By renovating the existing facilities instead of building new ones, and by implementing the landscape structures through architectural solutions, we could prevent the destruction of green areas that are of great importance for the preservation of biodiversity and quality environment.

Key words: sustainability, roof garden, vertical garden, landscape architecture

\section{NAPOMENA:}

Ovaj rad proistekao je iz master rada čiji mentor je bila dr Mirjana Sekulić, vanr. prof.

\section{UVOD}

Gustina naseljenosti počela je da prevazilazi planirane kapacitete, jer je urbana populacija u sve većem porastu. Više od polovine stanovnik Zemlje živi u urbanim područjima, odnosno gradovima koji zazuzimaju samo $3 \%$ ukupne površine.

Migracija stanovništva iz sela u gradove, industrijska revolucija, brzi razvoj tehnologija i nekontrolisano korišćenje prirodnih resursa su doveli do alarmantne ekološke situacije na planeti. Emisija ugljen dioksida se enormno povećala, zagađenje se prenelo i na vodu i hranu, pojavile su se nove bolesti, nestalo je mnogo biljnih i životinjskih vrsta zbog neprimerenog tretiranja otpada. Posledice se najviše osećaju u urbanim sredinama, jer je nagla urbanizacija zelene strukture svela na minimum. Sve to se najviše odražava, negativno, na psihofizičko zdravlje ljudi i kvalitet njihovog života.

Uloge zelenih struktura su raznovrsne: prvenstveno zdravstvena, a zatim socijalna, estetska, kulturna, edukativna itd. Zabrinjavajući je podatak da je količina zelenih površina po stanovniku u velikim gradovima Srbije nekoliko puta manja od prihvaćenih standarda, a posebno Pančeva.

Zbog sve veće gustine naseljenosti, cilj je obezbediti što kvalitetniju urbanu sredinu, a koja se postiže održivom i efikasnom upotrebom pejzažnih struktura, bilo horizontalnih ili vertikalnih.

Jedan od načina kvantitativnog povećanja vegetacije i ugradnje novih pejzažnih struktura u urbanim sredinama je ozelenjavanje krovnih površina (ekstenzivni i intenzivni krovni vrtovi), odnosno, vertikalnih vrtova. Ovo predstavlja samo jednu od mogućnosti da se izgubljena pejzažna struktura na neki način nadoknadi i ublaži šteta nastala nekontrolisanom gradnjom.

\section{PODELA KROVNIH VRTOVA}

Osnovna podela krovnih vrtova je na ekstenzivne i intezivne krovne vrtove. Ona je zasnovana na osnovu parametara kao što su tip izgradnje, način korišćenja, vrste vegetacije i održavanje.

\subsection{Ekstenzivni krovni vrtovi}

Ekstenzivno ozelenjavanje svodi se uglavnom na sukulente i nisko rastinje, koje ne zahteva posebnu negu i podnosi aridne uslove, visoku temperaturu, vetar i mraz. Biljni materijal treba da bude samoobnovljiv i prirodno regenerativan. Debljina supstrata varira od $8 \mathrm{~cm}$ do $15 \mathrm{~cm}$ i uglavnom se sastoji od mešavina na bazi mineralnih materija koje sadrže pesak, šljunak, lomljenu opeku, 
organske materije, treset i malo zemlje. Ekstenzivni krovni vrtovi mogu da se primenjuju kod krovova koji imaju minimalni nagib $1,5-2 \%$, pa sve do nagiba od $30^{\circ}$. Prosečna težina potpuno zasićenog ekstenzivnog krova je od 70 do 170 kilograma po kvadratnom metru [1]. Zbog male debljine supstrata većinu krovnih konstrukcija nije potrebno dodatno ojačavati.

Ekstenzivni krovni vrtovi prvenstveno predstavljaju ekološki krovni pokrivač. Imaju odlična termoizolaciona svojstva i služe za efikasno upravljanje atmosferskim vodama. Nisu prohodni, odnosno dostupni za posetioce. Pored tehničke, njihova namena je i estetske prirode.

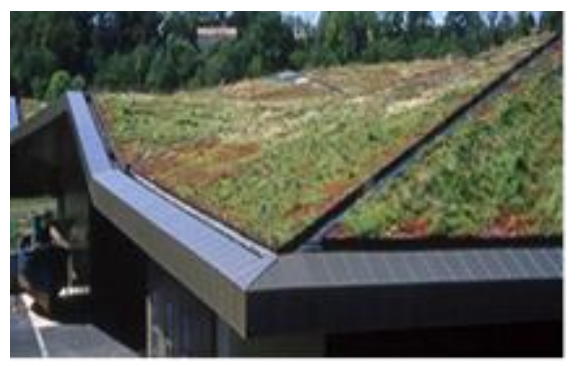

Slika 1. Primer ekstenzivnog krovnog vrta pod nagibom

\subsection{Intenzivni krovni vrtovi}

Glavna odlika intenzivnih krovnih vrtova je ta što su prohodni, pristupačni za posetioce. Najčešće su uređeni kao tradicionalni vrtovi ili parkovi, sa svim sadržajima koji su zastupljeni: staze, platoi, klupe i ostali mobilijar, pa i bazeni. Pokrivač se obično bazira na debljini supstrata od $20 \mathrm{~cm}$ do $60 \mathrm{~cm} \mathrm{[2].} \mathrm{Maksimalna} \mathrm{zabeležena}$ debljina je preko $4 \mathrm{~m}$. S porastom debljine supstrata povećava se i težina konstrukcije od 290 - 970 kilograma po kvadratnom metru, što podrazumeva obavezno ojačavanje konstrukcije objekta [3]. Izbor biljnih vrsta je raznovrsniji. Pored pokrivača tla, žbunja, puzavica, koriste se i srednja rastinja i niža stabla drveća što doprinosi kompleksnijem ekosistemu samog krova. Intenzivni krovni vrtovi su zahtevniji za održavanje. Pored intenzivne nege biljaka i održavanja krovne konstrukcije, iziskuju i posebne sisteme za navodnjavanje. Intenzivni krovni vrtovi predstavljaju skuplji izbor krovnog ozelenjavanja zbog svojih karakteristika što se tiče izgradnje, a i održavanja. To je razlog zbog koga se grade uglavnom na javnim objektima.
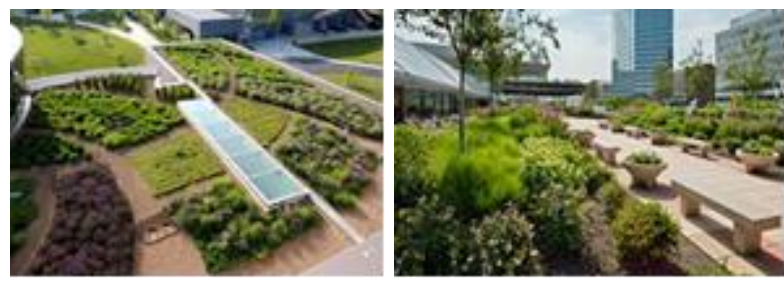

Slike 2 i 3. Primeri intenzivnog krovnog vrta

\section{PODELA VERTIKALNIH VRTOVI}

Osnovna podela vertikalnih vrtova je na zelene fasade $\mathrm{i}$ zelene zidove.

\subsection{Zelene fasade}

Zelene fasade se zasnivaju na primeni biljaka koje se penju duž zida ili vise sa njega. Biljke mogu da rastu naviše uz vertikalnu površinu, kao što su tradicionalni primeri, ili da rastu niz vertikalne površine, ukoliko su obešene na određenoj visini.
One se mogu klasifikovati kao direktne ili indirektne. Direktne zelene fasade su one na kojima su biljke pričvršćene direktno na zid. U njih spadaju tradicionalne zelene fasade koje se sastoje od samodržećih puzavica, direktno ukorenjenih u zemlji. Nemaju potpornu konstrukciju, oslanjaju se na svojstvo biljaka puzavica da se same pričvrste za vertikalnu površinu.

Indirektne zelene fasade uključuju vertikalnu potkonstrukciju za penjanje biljaka koje zapravo usmeravaju njihov rast, pružaju im potporu, povećavajući otpornost na ekološke uticaje i omogućavaju kombinovanje različitih vrsta biljaka, pri čemu se postiže raznovrsni dizajn vertikalnih površina. Prednost ovih sistema je što ne prianjaju direktno uz fasadu i tako sprečavaju eventualna moguća oštećenja do kojih dolazi zbog težine biljaka i mogućnosti da se lako odvoje od u slučaju potrebnih sanacija.

\subsection{Zeleni zidovi}

Zeleni zidovi omogućavaju brzo pokrivanje velikih površina i ravnomerniji rast biljaka duž vertikalnih površina, njihovo dostizanje do viših delova, prilagođavanje svim vrstama zgrada i integraciju velikog broja biljnih vrsta. Za razliku od zelenih fasada, zeleni zidovi zahtevaju više ulaganja (održavanje vegetacije, đubrenje, redovno navodnjavanje itd).

Sistemi zelenog zida mogu se klasifikovati kao kontinuirani ili modularni, prema načinu njihove primene. Kontinuirani sistemi su zasnovani na primeni lakih i propustljivih ekrana (panela) u kojima se biljke sade pojedinačno. Poznati su i kao ,vertikalne bašte“. Modularni sistemi su elementi sa specifičnim dimenzijom, koji uključuju rastuće medije u kojima biljke mogu da rastu. Svaki element je deo potporne konstrukcije ili je fiksiran direktno na vertikalnu površinu. Mogu se naći u vidu različitih kaseta, posuda, pločica ili fleksibilnih kesa. Razlikuju se prema svom sastavu i težini.

\section{ANALIZA RADA}

U potrošnji prirodnih resursa jednu do najvećih uloga imaju ugostiteljstvo i turizam. Ove dve grane predstavljaju najperspektivniji pokretač svetske privrede. Poseban izazov u hotelskoj industriji je taj, da ona radi 24 sata dnevno, 7 dana u nedelji, 365 dana godišnje. Za postizanje energetski efikasnog objekta, hoteli moraju prvenstveno da zadovolje određene mere za smanjenje uticaja na životnu sredinu. Održivost hotelskih objekata podjednako ima bitnu ulogu u namirivanju potreba svojih korisnika - stvaranju zdravog i prijatnog okruženja, smanjenju negativnog uticaja na životnu sredinu, kao i u poboljšanju poslovanja hotelske kompanije i stvaranju dobrog imidža. U radu je data komparativna analiza deset dobrih primera iz prakse svetskih hotela.

Opšte je poznato da se Pančevo doživljava kao crna ekološka mrlja. Sa sigurnošću se može reći da u njemu postoji stepen degradiranosti životne sredine, jer je u vazduhu prisutan veći broj zagađujućih materija.

Negativan uticaj na stanje i kvalitet vazduha, pored „klasičnih“ faktora kao što su neadekvatna saobraćajna rešenja i upotreba fosilnih goriva za zagrevanje $u$ zimskom periodu su i aero zagađenja kao rezultat proizvodno-tehnoloških aktivnosti u fabrikama naftnog, hemijskog i petrolejskog kompleksa. Prilikom duvanja 
dominantnog vetra zagađujuće materije se iz industrijske zone nanose ka stambenim naseljima. Primetno je zagađenje tokova Dunava, Tamiša i Nadele otpadnim vodama iz proizvodnih pogona u njihovoj blizini, kao i podzemnih voda. Zagađena voda, vazduh i zemljište predstavljaju faktore rizika okoline koji kontinuirano ugrožavaju zdravlje stanovništva.

Nivo ozelenjenosti u gradskom tkivu je zabrinjavajuće mali u odosu na normu za gradove na rekama (12 puta manji). Prosečna preporučena vrednost nivoa ozelenjenosti gradova Srbije je 30\%, a na teritoriji Pančeva ona iznosi $19,6 \%$.

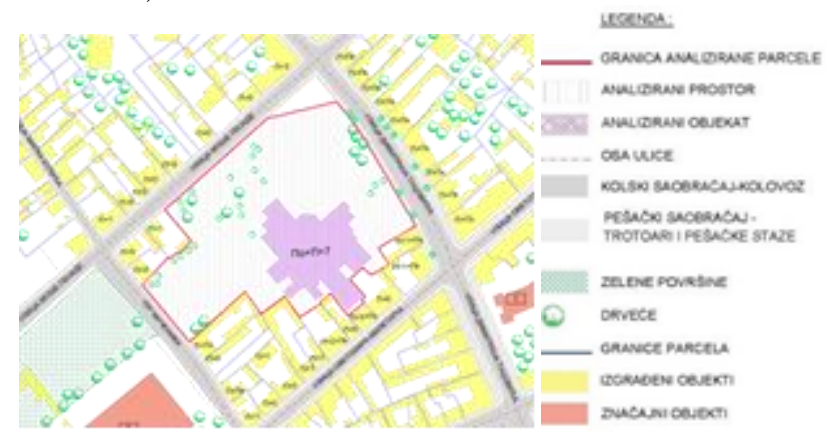

Slika 7. Analiza lokacije

\subsection{Postojeće stanje}

Sadašnje stanje pejzažno arhitektonskih struktura, odnosno prostora, u urbanim sredinama Pančeva je rezultat procesa nagle i nekontrolisane urbanizacije $\mathrm{u}$ godinama tranzicije. Posledice ovog procesa su smanjenje površina i kvaliteta zelenila $u$ gradu. $U$ radu je bio cilj da se kroz pejzažno - arhitektonsko uređenje postojećeg objekata hotela „Tamiš“ pokaže da se i pojedinačno može uticati na ekološku sliku grada.

Lokacija se nalazi na samom ulazu u grad Pančevo starim putem i na obodu centralne zone grada. Od starog gradskog jezgra, udaljena je pola kilometra. Fizičku strukturu okolnog gradskog tkiva čini tradicionalna blokovska gradnja pretežno individualnih objekata $\mathrm{P}+1$. Područje uz obalu Tamiša prirodno se nadovezuje na staro gradsko jezgro i sa njim čini potencijalno težište gradskog kulturnog, turističkog i rekreativnog života.

Hotel je sagrađen je 1978. godine. Spada u nestambenu kategoriju namenjenu turizmu i ugostiteljstvu, i predstavlja jedan od vizuelnih identiteta grada Pančeva [4].

Zgrada je slobodnostojeća i zauzima centralni deo bloka, spratnosti $\mathrm{Po}+\mathrm{P}+7$, sa ravnim krovom, razuđenog gabarita. Hotel nije zaklonjen od sunca i vetra, s obzirom na spratnost i udaljenost od susednih zgrada. Prisutno je minimalno zelenilo i nisko rastinje.

Zbog dugog perioda eksploatacije nakon izgradnje, objekat je u velikoj meri ruiniran sa vidnim oštećenjima.

\subsection{Novoprojektovano rešenje}

Projektom je planirano ozelenjavanje ravnih krovova prizemnih krila hotela, tačnije restorana, prvenstveno zbog smanjenja emisije $\mathrm{CO}_{2}$ i postizanja bolje mikro klime bloka, jer se nalazi na lokaciji koja je izložena povećanom aero zagađenju. Predviđeno je postavljanje modularnog zelenog krova - „Urbanscape“ sistema koji se sastoji od protivkorenske membrane, drenažnog sloja, supstrata - kamene mineralne vune koja ima odlična svojstva upijanja i zadržavanja vode, i vegetacije (https://www.knaufinsulation.rs). Krovni vrt je ekstenziv- nog tipa (nije prohodan), a od biljnog materijala najzastupljeniji su sedumi koji uspešno skladište vodu u svojim listovima, kao i druga vegetacija koja zahteva minimalno održavanje. Izuzetno je efikasan u sakupljanju atmosferskih voda - $1 \mathrm{~m}^{2}$ supstrata debljine $2 \mathrm{~cm}$ apsorbuje 17 litara kišnice, a zbog sposobnosti skladištenja vode obezbeđuje dugotrajno rashlađujuće dejstvo. To je vrlo bitan faktor što se tiče energetske efikasnosti, jer pomaže u smanjenju potrošnje energije od $25 \%$ pri grejanju i do $75 \%$ pri hlađenju i isto tako pruža dobru zvučnu izolaciju i tako stvara prijatnije okruženje.

Nedostatak drvoreda na trotoarima u ulici Dimitrija Tucovića i Moše Pijade se nadomešćuje sadnjom visokog i niskog rastinja na obodima parcele, koje ima višestruku ulogu, kao i drvoredima na svakom trećem parking mestu. Postavljanjem zelenila duž saobraćajnica postiže se zaštita od saobraćajnih zagađenja - izduvnih gasov. Parterno rastinje najviše upija prašinu iz vazduha, dok nisko rastinje štiti pešake od zagađenja. Kako je objekat slobodnostojeći i nezaštićen, krošnje drveća imaju ulogu prirodnog štita od uticaja vetra. Svakako, imaju i veliku ulogu zaštite od buke čiji su uzrok motorna vozila, jer se hotel nalazi na prometnoj saobraćajnici, na samom ulazu u grad.

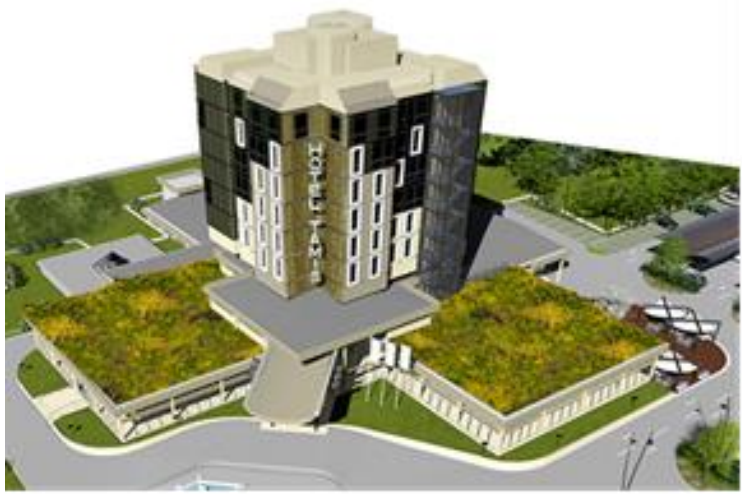

Slika 8. Novoprojektovani zeleni krov i bioreceptivni paneli na fasadi

Kombinacija zelenih struktura (površina) i krovnih vrtova ima značajnu ulogu u odvodnjavanju i prečišćavanju površinskih voda. One zadržavaju kišnicu i redukuju njeno oticanje čime se sprečavaju eventualna izlivanja $\mathrm{i}$ poplave u izgrađenim sredinama. Deluju kao prirodni filter za bilo koji tip vode koji se nađe na njima i tako vrše funkciju zaštite podzemnih voda. Smanjuju veliki broj zagađivača (čestice azota, motorna ulja, bakterije, teški metali) sa nepropusnih površina, kao što su trotoari, saobraćajnice i druge popločane površine, koje se tokom padavina spiraju, prenose i ulivaju u površinske vode.

Veliki značaj zelenih površina u prečišćavanju voda je zbog toga što se u prirodnom vodenom ciklusu veći deo atmosferskih voda infiltrira $u$ prirodi, a manji deo se odvodi kanalizacijom. Na taj način se podzemne vode prirodno obnavljaju i održava se biološka mikroklima. Vodotok Tamiš je ekološki koridor od regionalnog značaja i zbog toga je važno poboljšati njegove prirodne fizičke osobine vode, koje su često vrlo zagađene, ali i obale.

$\mathrm{Na}$ osnovu urađene analize vizura, utvrđeno je da su objekti u ulici Dimitrija Tucovića i Moše Pijade lošijeg boniteta i da postavljanje visokog rastinja ne utiče na zaklanjanje povoljnih vizura. Što se tiče hotela koji ima reperni karakter, vizura nije narušena - ostaće vidljiva sa mosta na ulasku i grad i sa drugih mesta. 
Vizuelna percepcija celog hotelskog kompleksa će biti posebno atraktivna za goste hotela, čiji se pogled iz soba pruža nad njim. Usklađenom kombinacijom pejzažnih struktura postižu se bolji higijenski uslovi i bolji estetski efekti [5].

Jedan od doprinosa poboljšanju životne sredine imaju inovativni sistemi fasadnih panela implementirani na severozapadnoj fasadi. Ovi paneli se zasnivaju na bioreceptivnim materijalima, odnosno betonu izmenjenog hemijskog sastava, koji omogućava rast mikroorganizama na svojoj površini. Posebne je hrapavosti i poroznosti, što znači da apsorbuje vodu i podržava širenje mikroorganizama koje se razmnožavaju preko spora kao što su mahovine, gljive i lišajevi.

Gornji, poslednji, sloj je obrnuti hidroizolacijski premaz koji omogućava prikupljanje i skladištenje kišnice u organskom (bioreceptivnom) sloju [6]. Posebna prednost bioreceptivnih panela jeste to što se zbog karakteristika mikroorganizama, koji se razvijaju na njima, postavljaju na neosunčanim stranama - severu i zapadu. Paneli se transformišu tokom sva četiri godišnja doba - menjaju boje i teksture. Ovaj princip je dosta jednostavniji i pristupačniji od vertikalnih vrtova, jer nije potrebno nikakvo održavanje, niti su potrebni sistemi za navodnjavanje.

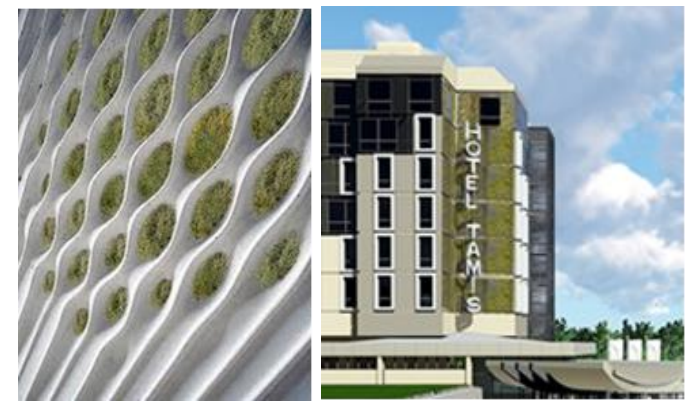

Slike 09 i 10. Bioreceptivni fasadni paneli

Pored krovnih vrtova, bioreceptivnih panela i pejzažnog uređenja, primenjeni materijali i oprema zadovoljavaju najviše standarde iz oblasti energetske efikasnost i ekologije. Energetska efikasnost je postignuta kroz energetsku sanaciju fasade hotela i njenu rekonstrukciju. Svi elementi termičkog omotača su sanirani. Spoljašnja stolarija i bravarija je u potpunosti uklonjena i postavljena je nova.

\section{ZAKLJUČAK}

Energetska efikasnost je najvažnija mera koja omogućava rešavanje tri aktuelna problema današnjice - ekološki, energetski i problem životne sredine. Sanacijom postojećih objekata, umesto izgradnjom novih, sprečava se uništavanje zelenih struktura koje su od izuzetnog značaja za očuvanje biodiverziteta i kvalitetne životne sredine.
Pejzažno - arhitektonsko uređenje kompleksa hotela „Tamiš“ primer je pojedinačnog (tačkastog) unapređenja ekološke slike Pančeva i neutralizovanje crne ekološke mrlje. Strategije koje se baziraju na principima održivog razvoja doprinose zaštiti klime, uštedi energije i obezbeđuju bolji kvalitet života za stanovnike. Svakako, neophodno je sagledati problematiku, još detaljnije, $u$ širem kao i užem kontekstu (klimatske promene, transport, buka, otpad, problem vode, biodiverzitet, javne zelene površine i upravljanje zaštitom životne sredine), kao i sam prizvodno-tehnološku proces hotela, ali to prevazilazi motiv izrade ovog rada.

\section{LITERATURA}

[1] Peck, S., Kuhn M., Design Guidelines for Green Roofs. National Research Council Canada, Toronto, 2001.

[2] G. Grant, "Green Roofs and Facades", IHS BRE Press, 2006.

[3] Oberndorfer E., J. Lundholm, B. Bass, R.R. Coffman, H. Doshi, N. Dunnett, "Green roofs as urban ecosystems: Ecological structures, functions, and services", American Institute of Biological Sciences, 2007.

[4] Službeni list grada Pančeva br.28 godina (12.oktobar 2016.godine) - Plan generalne regilacije (PGR)

[5] Vukajlov, Lj., „Uvod u urbanizam“, FTN, Novi Sad, 2015.

[6] Ferrándiz-Mas, V., "Science of the total environment", volumes 563-564, pp. 71-80, 2016.

\section{Kratka biografija:}

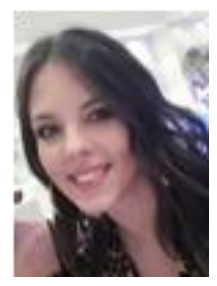

Anđela Aleksandrov rođena je u Beogradu 1990. godine. Osnovne akademske studije završila 2014. godine na fakultetu Union - Nikola Tesla. Master studije završava 2019. godine na Departmanu za arhitekturu i urbanizam, smer Arhitektonsko i urbanističko projektovanje.

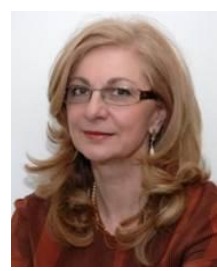

Mirjana Sekulić rođena 1955. godine u Zemunu. Doktorsku disertaciju pod nazivom „Razvoj i transformacije krovnog vrta od nastanka do savremenih tendencija" odbarnila je 2013. godine. Oblast interesovanja je pejzažna arhitektura. Vanredni je profesor na Departmanu za arhitekturu i urbanizam FTN u Novom Sadu. 